\title{
EFFECTS OF MODELLING PARAMETERS ON THE SEISMIC ANALYSIS OF BRIDGES
}

\author{
YULING GAO \& LAN LIN \\ Department of Building, Civil and Environmental Engineering, Concordia University, Canada.
}

\begin{abstract}
The objective of this study is to investigate the effects of the uncertainties of major modelling parameters on the bridge seismic response. The parameters examined include the superstructure mass, concrete compressive strength, plastic hinge length and damping. For the purpose of the evaluation, an existing 3-span reinforced concrete highway bridge located in Montreal, Canada, was selected for the analysis. A three-dimensional model of the bridge was developed using SAP2000. Nonlinear time-history analyses were conducted in order to assess the effects of the uncertainty of each of modelling parameters mentioned above. Fifteen records obtained from earthquakes around the world were used as seismic excitations in the time-history analysis. The deck displacement and the column curvature ductility were chosen to investigate the effect of the uncertainty of the modelling parameters on the seismic response of the bridge.

Keywords: bridge, finite element, modelling, nonlinear, records, responses, seismic, uncertainty.
\end{abstract}

\section{INTRODUCTION}

Earthquakes are one of the main natural hazards that have caused devastations to bridges around the world. Given the observations from past earthquakes, substantial analytical and experimental research work related to bridges has been undertaken in Canada and other countries. The analytical research is focussed primarily on the prediction of the seismic performance of existing bridges. It includes bridge-specific investigations that are mainly conducted using deterministic approach, and investigations of bridge portfolios that are based on probabilistic approach. In both cases, nonlinear time-history analyses are extensively used. To conduct analysis on a given bridge, analytical (i.e. computational) model of the bridge is required. It is known that the seismic response predictions depend greatly on the accuracy of the input of the parameters considered in the bridge model.

A number of parametric studies were conducted in the past to evaluate the effects of modelling parameters on the seismic response of bridges in North America. Choi et al. [1] conducted a study on the effects of the material properties on four typical bridges including two multi-span simply supported bridges (one is steel, the other is pre-stressed concrete), and two multi-span continuous bridges. They concluded that fixed bearings in multi-span simply supported steel girder-type bridges were more vulnerable to earthquakes than any other components. Padgett et al. [2] performed seismic analysis on a multi-span simply supported steel girder bridge. The purpose of their study was to investigate the effects of restrainer cables; effective stiffness of elastomeric bearings; yield strength of the steel jackets; and the reinforcing of the shear keys on the bridge behaviour. They reported that the bearing stiffness, rotational stiffness of the foundation, and the gap width had significant effects on the bridge response. Some studies focussed on a specific modelling parameter on structure response, e.g. number of spans [3]; incident angle of seismic motions [4]; modelling techniques for abutments [5]; etc.

Our study is mainly focussed on the parameters that would affect the dynamic characteristics and nonlinear behaviour of the bridge models, namely, superstructure mass, concrete 
compressive strength, plastic hinge length, damping, yield strength of the reinforcing steel, yield displacement of the bearing and post-yield stiffness of the bearing. However, only the results for the first four modelling parameters are presented in this paper due to the page restrain.

\section{BRIDGE DESCRIPTION}

A three-span continuous reinforced concrete bridge (Fig. 1) located in Montreal, Canada was selected for the study. The bridge was built in 1982. The total length is $45.5 \mathrm{~m}$, which consists of two end spans of $15 \mathrm{~m}$ each and a middle span of $15.5 \mathrm{~m}$. The overall deck width is $16.85 \mathrm{~m}$. It is a straight bridge without skew angle. The bridge is considered to be representative of typical highway bridges in Québec according to Tavares [6].

As shown in Fig. 1, the superstructure of the bridge consists of a slab supported by seven 900 C.P.C.I girders (Canadian Precast Prestressed Concrete). The thickness of the slab is $225 \mathrm{~mm}$, and the center-to-center spacing of girders is $2.4 \mathrm{~m}$. The concrete deck is reinforced with $15 \mathrm{M}$ bars on the top and bottom. There are 6 straight tendons and 8 parabolic tendons on the bottom of each girder across each span. The cross section of the cap beam is $1 \mathrm{~m}$ wide, and $1.2 \mathrm{~m}$ deep. The multi-column bents consist of three rectangular columns. The center-tocenter spacing between columns is $5.3 \mathrm{~m}$. The dimensions of each column are $1 \mathrm{~m}$ (in the transverse direction) $\times 0.75 \mathrm{~m}$ (in the longitudinal direction). The average height of the column is $3.8 \mathrm{~m}$. Each column is reinforced with 16-30M bars providing longitudinal reinforcement ratio of $1.49 \%$. Column ties with $15 \mathrm{M}$ at a spacing of $300 \mathrm{~mm}$ were used as transverse reinforcement. The transverse reinforcement ratio is about $0.24 \%$. Strip footing is used for the column bents. Seat-type abutments are on a pile foundation, as illustrated in Fig. 1. Expansion bearings are used at abutments and the pier 2, while fixed bearings are used at the pier 1 . All the concrete members were designed using the compressive strength $\mathrm{f}_{\mathrm{c}}^{\prime}=30 \mathrm{MPa}$ except $35 \mathrm{MPa}$ was used for the girders, while the yield strength of the reinforcing steel bars was assumed to be $400 \mathrm{MPa}$.
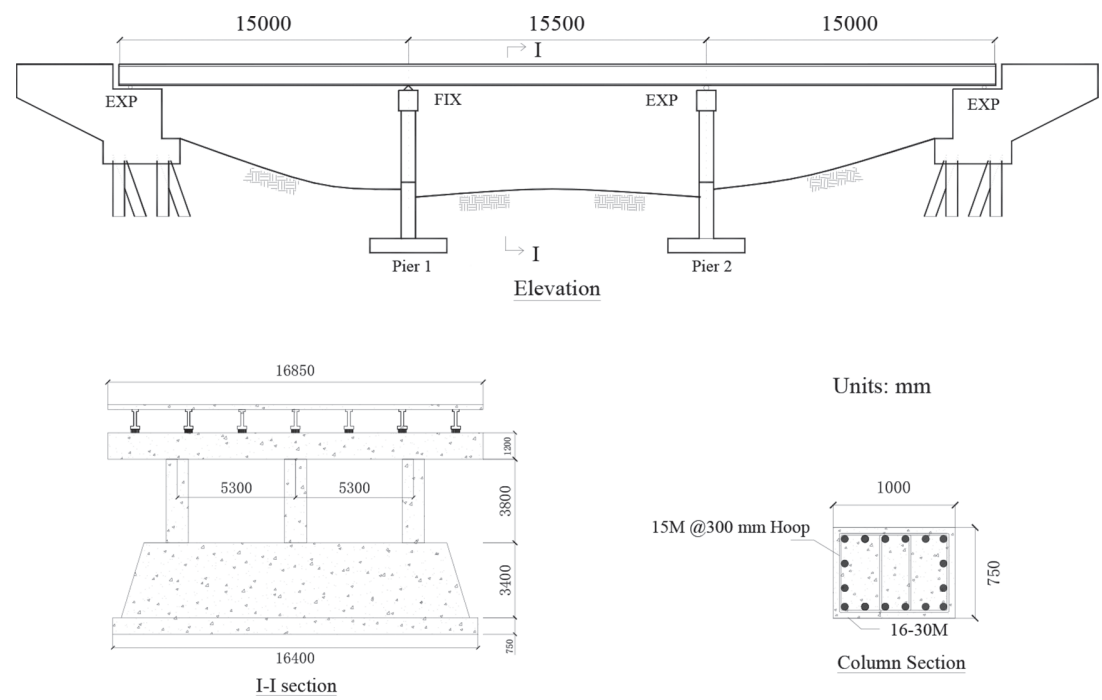

Figure 1: Configuration of the examined bridge. 


\section{BRIDGE MODELLING}

In this study, a three-dimensional finite element model of the bridge was developed using the structural analysis software SAP2000 [7]. The advantage of SAP2000 is that a number of elements (e.g. link element) are available that can be used to model the nonlinearity of different components of a bridge system during seismic excitations including bearings and plastic hinges. It is necessary to mention that another program OpenSees [8] can also be used for the nonlinear analysis of bridges. However, a study conducted by Aviram et al. [5] showed that these two programs provided very similar results. SAP2000 was selected in this study due to its simplicity in modelling and less time consuming in the analysis compared with OpenSees.

\subsection{Superstructure}

The superstructure of the bridge was modeled as one line of elastic beam elements (Fig. 2), which is referred to as spine model in SAP2000. Each span is discretized into 10 equal segments in order to achieve higher accuracy of results though only four elements per span are required for modeling the superstructure in accordance with ATC 32 [9]. The section properties, such as the cross-sectional area, moment inertia, shear area and torsional constant of the superstructure, were determined based on the geometry presented in Fig. 1. In this study, a factor of 0.75 was applied to reduce the moment of inertia of the deck section, and no reduction factor was applied for the girder's sections according to Caltrans Seismic Design Criteria [10]. Furthermore, reduction of the torsional moment of inertia was not considered since the bridge is regular [10].

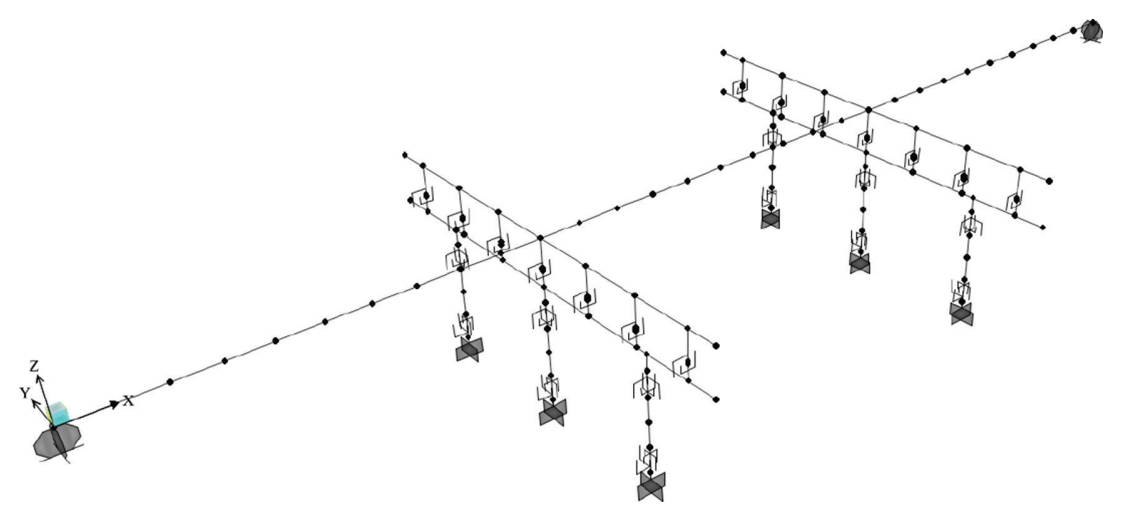

Figure 2: Finite element model of the bridge.

\subsection{Bearing}

Figure 3 presents an idealized bilinear curve representing the behaviour of the expansion bearing in the longitudinal direction, as recommended by Kelly [11] and DesRoches et al. [12]. Parameters $\mathrm{K}_{1}$ and $\mathrm{K}_{2}$ denote the initial shear stiffness (i.e. elastic stiffness) and post-yield stiffness, respectively. In this study, $\mathrm{K}_{1}$ was calculated using eqn (1), while $\mathrm{K}_{2}$ was taken as one-third of $\mathrm{K}_{1}$, as suggested by DesRoches et al. [12]. Parameters $\mathrm{D}_{\mathrm{y}}$ and $\mathrm{D}_{\mathrm{u}}$ represent the yield displacement and maximum displacement of the bearing, respectively. Following the recommendations made by DesRoches et al. [12], $\mathrm{D}_{\mathrm{u}}$ was assumed to be equal to the height of the elastomer, while $\mathrm{D}_{\mathrm{y}}$ was taken as $10 \%$ of $\mathrm{D}_{\mathrm{u}}$. 


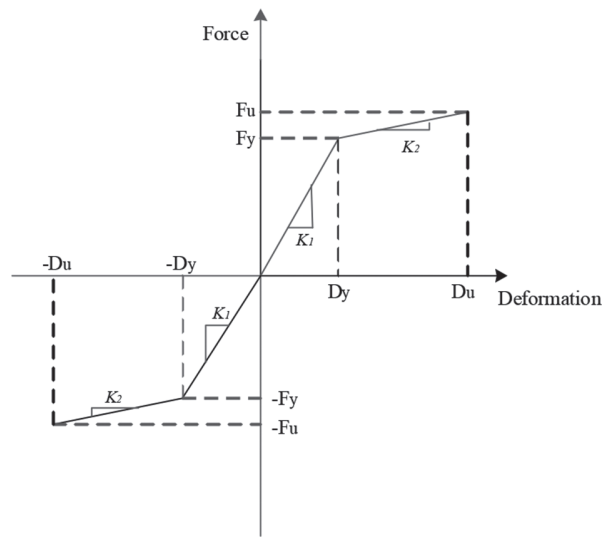

Figure 3: Bilinear behaviour of elastomeric bearings in the longitudinal direction.

$$
K_{1}=\frac{G A}{H_{r}}
$$

- $G=$ shear modulus, which is taken as 0.80 MPa based on Caltrans [10].

- $A=$ plan area of the elastomeric pad.

- $H_{r}=$ total thickness of the rubber.

\subsection{Column and cap beam}

Plastic hinges are expected to form on the bottom and/or the top of columns during larger earthquake events. In this study, the length of the plastic hinge was determined according to the seismic provisions of CHBDC [13]. For the purpose of defining the link element in SAP2000, which was used to simulate the behaviour of column in the plastic hinge region, moment-curvature relationships for the end sections of the column were developed using fibre analyses of the cross sections. The concrete stress-strain relationship including the effect of confinement was determined based on the model proposed by Mander et al. [14]. Nominal values for the material strengths were used in the fibre analysis, i.e. concrete and reinforcement resistance factors $\Phi_{\mathrm{c}}=\Phi_{\mathrm{s}}=1$. In addition, the axial force used to develop the moment-curvature relationship includes the force resulting from the dead load only. Based on the computed moment-curvature relationship, Multi-linear kinematic plasticity model defined in SAP2000 was selected to model the column in the plastic hinge regions. The column was assumed to behave elastically outside the plastic hinge regions. In total, each column was divided into five equal segments.

Rigid bars were used to connect the nodes between superstructure and bearings, bearings and columns, bearings and cap beams, and cap beams and columns. The bottom of the columns was assumed to be fully fixed.

\subsection{Abutment}

Model of the abutment has a significant impact on the nonlinear response of bridges during earthquake events [15, 16]. Recently Aviram et al. [5] conducted a comprehensive 
investigation of the effect of abutment modelling on the seismic response of bridges. In their study, three abutment models were examined, which were roller model, simplified model, and spring model. It was found that the dominant periods of the examined bridges based on the three models were relatively close except that the first mode period using the spring model was significantly shorter than that using the other two models. Given this, the roller model was selected for this study due to its relatively low modelling complexity.

\section{SEISMC EXCITATIONS}

Since the lack of strong ground motion records in eastern Canada, Naumoski et al. [17, 18] compiled a number of records obtained from earthquakes around the world, which were considered representative of the characteristics of the ground motions in eastern Canada. These records were grouped into three ensembles, namely, high $\mathrm{A} / \mathrm{V}$, intermediate $\mathrm{A} / \mathrm{V}$, and low $\mathrm{A} / \mathrm{V}$ according to the ratio of the peak ground acceleration A (in $\mathrm{g}$ ) to peak ground velocity $\mathrm{V}$ (in $\mathrm{m} / \mathrm{s}$ ). As reported in Naumoski et al. [17, 18], ground motions in eastern Canada were typically characterized by high frequency content and high $\mathrm{A} / \mathrm{V}$ ratios. Therefore, the high A/V ensemble was selected for this study. It consists of 15 pairs of horizontal and vertical records. It is necessary to mention that the vertical records were not considered in the analysis because the vibration of the bridge model was not governed by the vertical mode. The magnitudes of the selected records were between 5.3 and 6.9, and distances from $4 \mathrm{~km}$ to $26 \mathrm{~km}$. These ranges cover the dominant magnitude and distance ranges that have the largest contribution to the seismic hazard in Montreal [19].

Figure 4 presents the $5 \%$ damped response spectra of the selected records scaled to the spectral acceleration at the fundamental period $\mathrm{T}_{1}=0.99 \mathrm{~s}$ of the bridge model. For the purpose of comparison, the design spectrum for Montreal for the probability of exceedance of $10 \%$ in 50 years for soil profile type I (i.e. rock or stiff soil) is also shown in the figure. It can be seen in Fig. 4 that the mean spectrum of the selected records exceeds the design spectrum for the periods shorter than $1.0 \mathrm{~s}$, and it is slightly below the design spectrum for the periods longer than $1.0 \mathrm{~s}$.

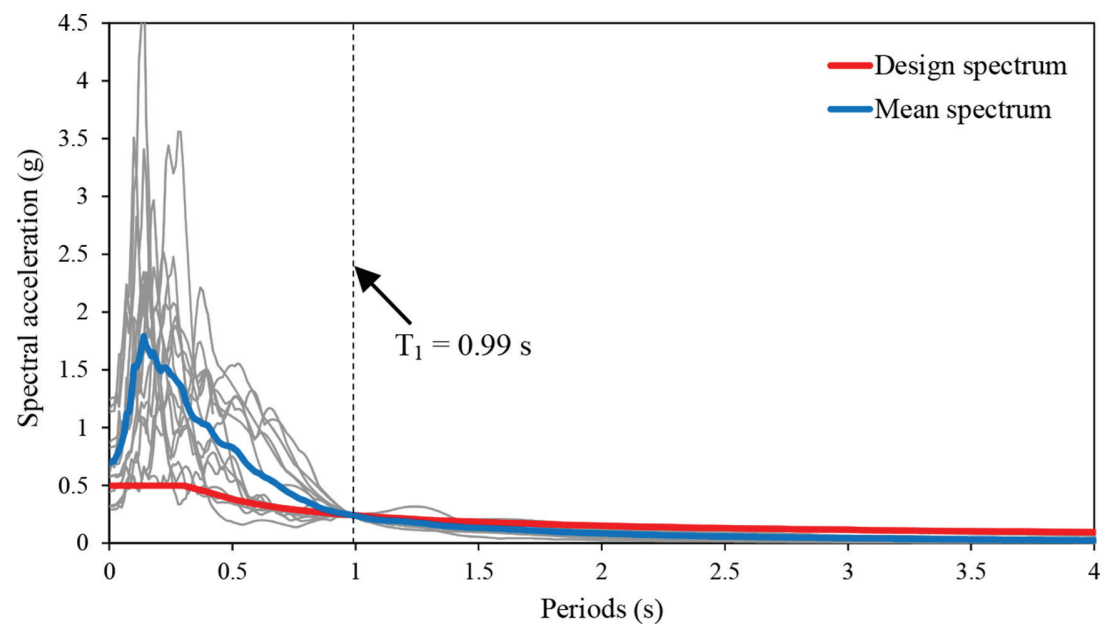

Figure 4: Scaled response spectra of the records, $5 \%$ damping. 


\section{ANALYSIS RESULTS}

Nonlinear time-history analyses were conducted by subjecting the bridge model to the selected records scaled at a series of excitation levels from $0.2 \mathrm{Sa}(0.99 \mathrm{~s})$ (i.e. $0.048 \mathrm{~g}$ ) to $5.0 \mathrm{Sa}(0.99 \mathrm{~s})$ (i.e. $1.20 \mathrm{~g})$. These intensity levels were selected in order to cover a wide range of the bridge response from elastic to inelastic. The response parameters considered in the study are the deck displacement and the column curvature ductility that represent the global deformation and local deformation, respectively. Table 1 provides the nominal value of each modelling parameter under investigation along with its variation.

For each excitation motion, the maximum value of each response parameter was computed. Given a large number of analyses conducted in the study, it is not practical to consider the response from a single time-history analysis. Therefore, the responses resulting from the set of excitations were statistically analysed to compute the mean (M) value. The use of the mean values is considered appropriate because these values are more 'stable' (i.e. they have smaller variations) than the mean plus one standard deviation $(\mathrm{M}+\mathrm{SD})$ values.

\subsection{Effects of the superstructure mass}

Figure 5a shows the results of the deck displacement corresponding to the different superstructure mass from $70 \%$ to $130 \%$ of its nominal value, at 11 intensity levels. Each point in the figure represents the maximum mean displacement at a given excitation level. The main observation of the results is that the deck displacement increases with the increasing of the superstructure mass. It should be noted that the change of the superstructure mass by $\pm 30 \%$, with respect to its nominal value, shifts the fundamental period $\mathrm{T}_{1}$ of the bridge slightly. However, this shifting has negligible effect on the design spectral acceleration. As a result, the inertia force is directly proportional to the superstructure mass. It can be seen in Fig. 5a that the superstructure mass does not affect the deck displacement for the excitations lower than about $0.50 \mathrm{~g}$, which is equivalent to $2.0 \mathrm{Sa}(0.99 \mathrm{~s})$. Beyond this level, the effect becomes noticeable. Furthermore, it is found that change of the superstructure mass by $30 \%$ causes the change of the displacement by $10 \%$ at the highest intensity level $5.0 \mathrm{Sa}(0.99 \mathrm{~s})$.

The results for the column curvature ductility at pier 1 (Fig. 1) are presented in Fig. 5b. It can be seen in the figure that the column behaves elastically (ductility $=1.0$ ) for the excitations up to the design earthquake level at $\mathrm{Sa}(0.99 \mathrm{~s})=0.24 \mathrm{~g}$. Furthermore, the ductility is proportional to the ratio of the intensity level to the design spectral acceleration at $\mathrm{Sa}(0.99 \mathrm{~s})$. For example, the ductility of 3 approximately corresponds to the ground motions of three times $\mathrm{Sa}(0.99 \mathrm{~s})$ which is about $0.72 \mathrm{~g}$. It is necessary to mention that the force reduction factor used for the design of the bridge substructure is 3 according to CHBDC [13]. The

Table 1: List of nominal values and variations of uncertainties considered.

\begin{tabular}{lll}
\hline Modelling parameters & Nominal value & Variation \\
\hline $\begin{array}{l}\text { Superstructure mass } \\
\text { Concrete compressive }\end{array}$ & $\begin{array}{l}100 \% \text { of the mass based on the geometry } \\
\text { strength }\end{array}$ & $\begin{array}{l}70 \% \sim 130 \% \\
20 \mathrm{MPa}\end{array}$ \\
$\begin{array}{l}\text { Plastic hinge length } \\
\text { Damping }\end{array}$ & $1.0 \mathrm{~m}$ & $\begin{array}{l}1.0 \mathrm{~m} \sim 1.5 \mathrm{~m} \\
2 \% \sim 8 \%\end{array}$ \\
\hline
\end{tabular}



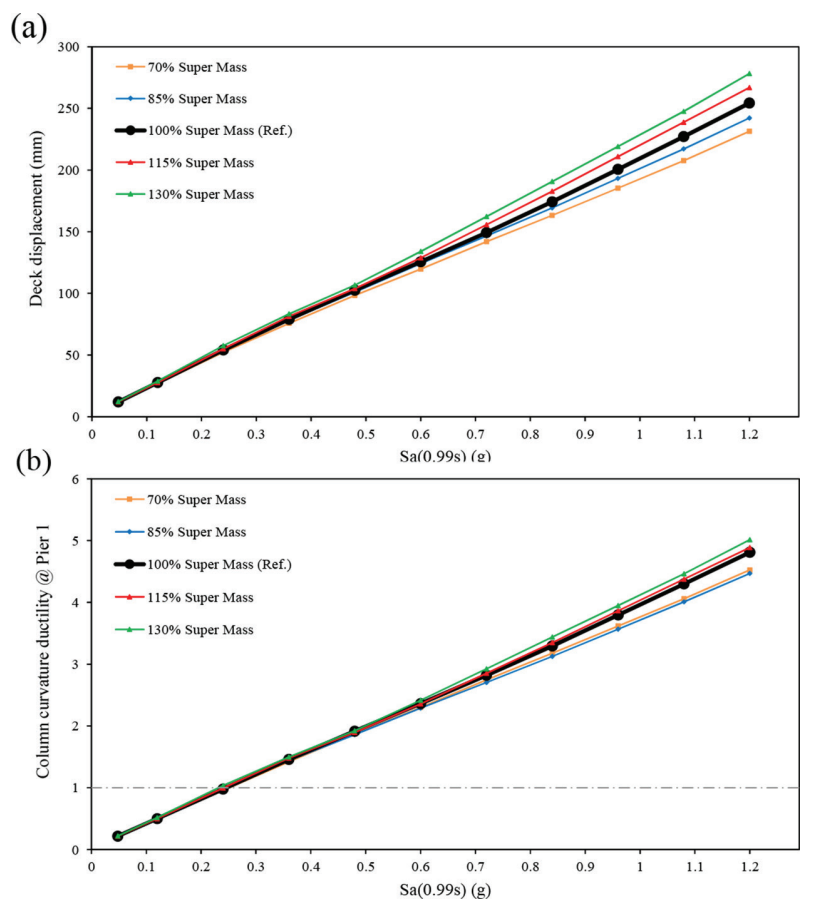

Figure 5: Responses due to change of the superstructure mass, (a) deck displacement; (b) column curvature ductility.

results in the figure clearly show that the columns on the bridge have satisfactory behaviour, i.e. they could survive in an earthquake event about 3 times the design earthquake. The acceptable performance of the substructure is mainly because the bridge was retrofitted in 1990s to improve its seismic resistance by replacing the original bearings with elastomeric bearings. Otherwise it would have sustained at least major damage under the design earthquake considering the bridge was quite old. Overall the $30 \%$ change of the superstructure mass on average leads about $5 \%$ difference on the pier ductility.

\subsection{Effects of the concrete compressive strength}

The uncertainty of the material property is one of the major factors that need to be taken into account in the development of the fragility curves for bridges $[1,6,20]$. It is known that the concrete compressive strength $\left(f_{c}{ }^{\prime}\right)$ would affect the result of the moment-curvature or moment-rotation relationship of a given reinforced concrete section, which represents the hysteretic behaviour of the section under seismic loading. Given this, sensitivity analyses were conducted in this study for different $\mathrm{f}_{\mathrm{c}}{ }^{\prime}$ for the column, such as $20 \mathrm{MPa}, 25 \mathrm{MPa}$, $30 \mathrm{MPa}, 35 \mathrm{MPa}$ and $40 \mathrm{MPa}$. The responses corresponding to $\mathrm{f}_{\mathrm{c}}{ }^{\prime}=30 \mathrm{MPa}$ were considered as a reference.

The results for the deck displacement and column curvature ductility are presented in Fig. $6 a$ and b, respectively. The results in Fig. 6a show that smaller $\mathrm{f}_{\mathrm{c}}{ }^{\prime}$ provides larger deck displacement and vice verse. However the variation in the responses is quite small, i.e. less than $5 \%$ with respect to the reference at the highest intensity level of $5.0 \mathrm{Sa}(0.99 \mathrm{~s})$. Such 

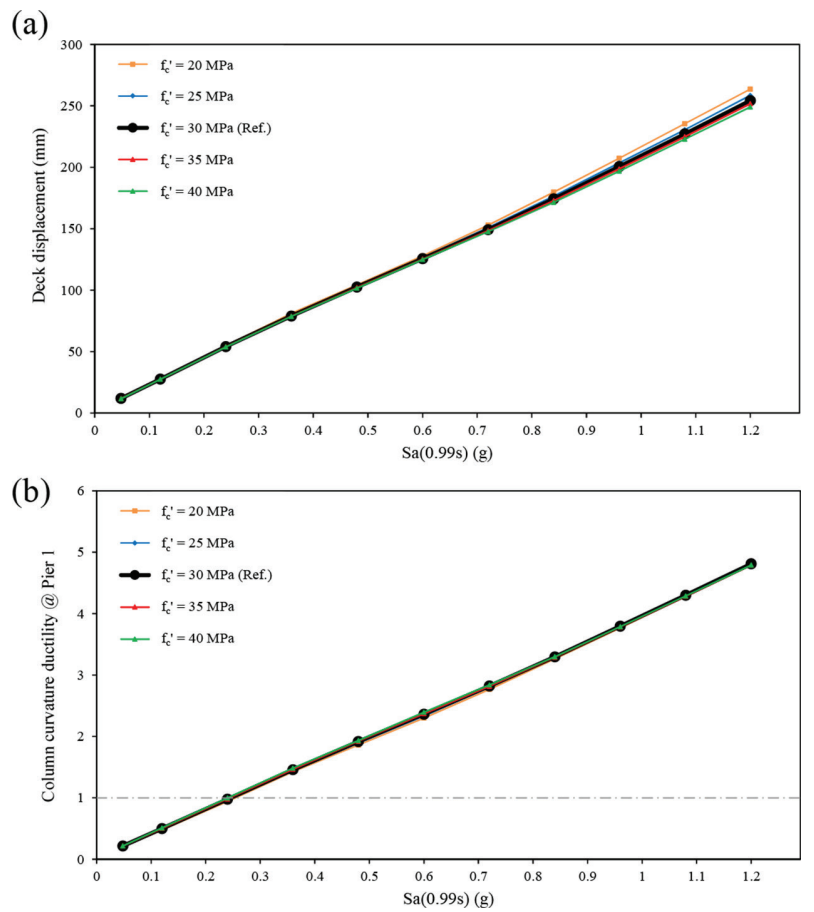

Figure 6: Responses due to change of the concrete compressive strength, (a) deck displacement; (b) column curvature ductility.

results were expected because the variation of the concrete strength mentioned above was only assigned to the column that affects the nonlinearity of the plastic hinge, and not to the deck and the girder. In addition, the superstructure should behave elastically according to the capacity design principle for bridges [13]. The small difference between the responses was due to the change of the stiffness of the substructure arising from different $f_{c}{ }^{\prime}$. The results in Fig. $6 b$ indicate that $f_{c}{ }^{\prime}$ does not have effect on the curvature ductility of the column at pier 1 , where fixed bearings are used. This is because the bearing carries most of the seismic force given its relatively larger lateral stiffness.

\subsection{Effects of the plastic hinge length}

In order to evaluate the effect of plastic hinge length on the bridge response, the plastic hinge length $\left(\mathrm{L}_{\mathrm{p}}\right)$ was varied by a factor of 1.1 to 1.5 times its normal value of $1 \mathrm{~m}$ determined according to CHBDC, and they are $1.0 \mathrm{~m}, 1.1 \mathrm{~m}, 1.2 \mathrm{~m}, 1.3 \mathrm{~m}, 1.4 \mathrm{~m}$ and $1.5 \mathrm{~m}$. Figure $7 \mathrm{a}$ shows the results for the deck displacement, while Fig. $7 \mathrm{~b}$ for the column curvature ductility. It can be seen clearly in Fig. 7a that the change of the plastic hinge length does not affect the deck displacement. Such observation is not surprising due to the mechanism of a bridge system, i.e. the displacement of the superstructure should be equal to the displacement of the substructure. Another observation of the results is that the increase of the maximum mean deck displacement is almost linearly proportional to the increase of the seismic excitation level.

As shown in Fig. 7b, the curvature ductility decreases with the increase of the plastic hinge length. For example, at the seismic excitation of $0.90 \mathrm{~g}$, the column curvature ductility 

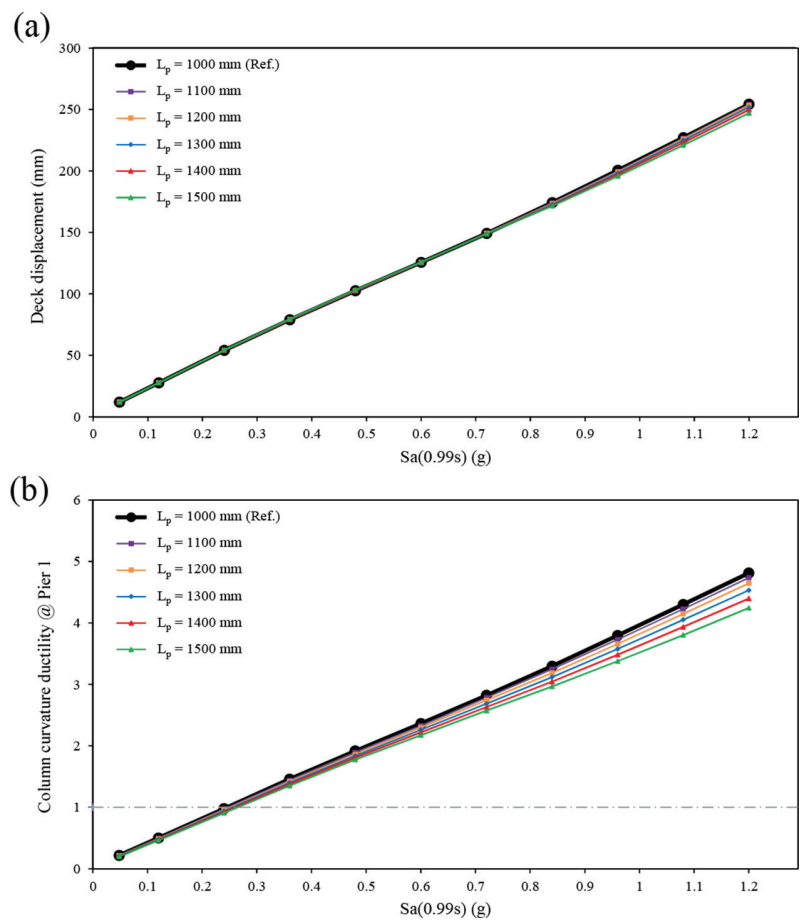

Figure 7: Responses due to change of the plastic hinge length, (a) deck displacement; (b) column curvature ductility.

corresponding to $\mathrm{L}_{\mathrm{p}}=1.0 \mathrm{~m}$ (i.e. the reference value) is about 2.8 , while it is about 2.6 corresponding to $L_{p}=1.5 \mathrm{~m}$, which gives a difference about $10 \%$. It should be noted that similar results were observed from the results of pier 2 (under the expansion bearing) that are not presented in this paper. Furthermore, it was found in this study that the column curvature ductility of pier 1 (under the fixed bearing) was about 2.5 times larger than that of the pier 2. It indicates significant inelastic deformations occurred in pier 1 due to larger seismic force applied.

\subsection{Effects of the damping}

In the bridge modelling, Rayleigh damping was selected in order to take into account the bridge stiffness degradation during nonlinear response while a constant damping was assigned to all the 12 vibration modes. For the purpose of the investigation, the variation of damping ranged from $2 \%$ to $8 \%$, in which the $5 \%$ damping was considered as a reference to compare the analysis results, as presented in Fig. 8.

As expected, smaller damping provides larger response, while larger damping creates smaller response. Detailed calculations showed that change of the damping by $1 \%$ would create variation on average about $3 \%$ in the deck displacement and column curvature ductility. In addition, the analysis results show that damping has significant effects on flexible columns at lower excitation levels. For example, the curvature ductility of the column at pier 2 resulting from $2 \%$ damping is about $17 \%$ larger than the reference value at the intensity level of $1.0 \mathrm{Sa}(0.99 \mathrm{~s})$. However, it is only $9 \%$ larger than the reference ductility at the excitation level of $5.0(0.99 \mathrm{~s})$. 

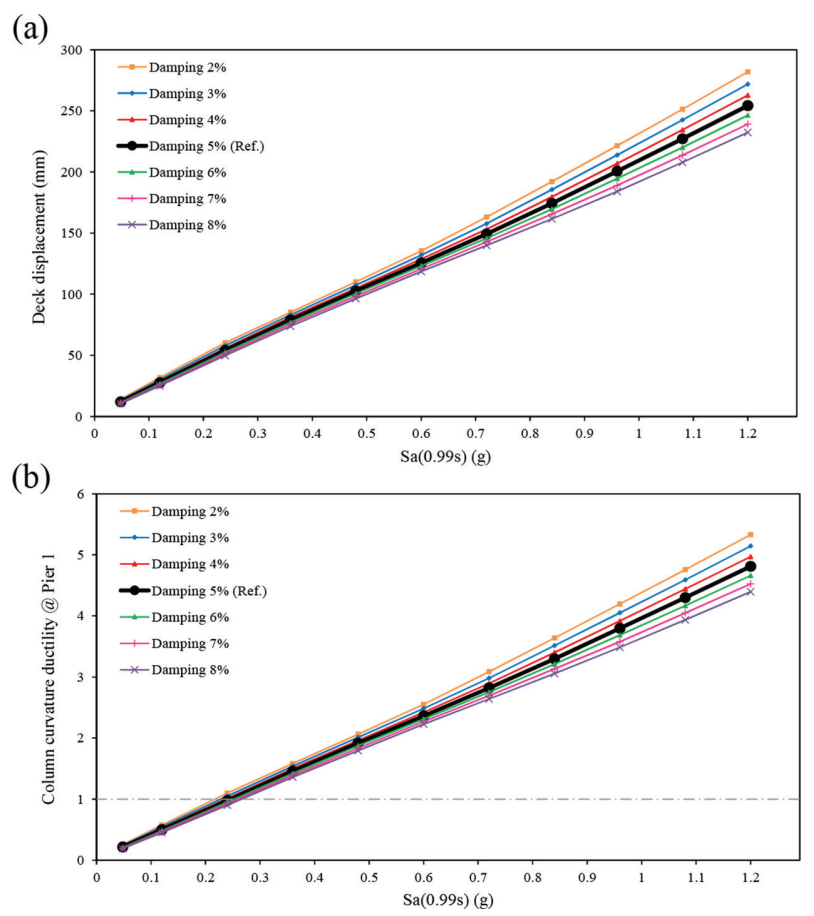

Figure 8: Responses due to change of the damping, (a) deck displacement; (b) column curvature ductility.

\section{CONCLUSIONS}

In this study, effects of the uncertainties of the superstructure mass, concrete compressive strength, plastic hinge length, and damping on the bridge seismic response were investigated. The sensitivity analysis on each modelling parameter was conducted on a 3-span reinforced concrete highway bridge located in Montreal, Canada. In total, 15 records obtained from the earthquakes around the world were used in the nonlinear time-history analysis. The deck displacement and the column curvature ductility were selected to represent the bridge response. The main conclusions from the study are summarized as follows:

- Changing the superstructure mass by $30 \%$ causes the deck displacement to change about $10 \%$ at the seismic excitation level five times the design earthquake while it does not have effect on the column curvature ductility.

- Changing the concrete compressive strength does not affect the deck displacement and column curvature ductility under the fixed bearing.

- Changing the plastic hinge length does not affect the deck displacement. However, it does affect the column curvature ductility, i.e. larger plastic hinge length provides smaller curvature ductility. Furthermore, increase in the plastic hinge length by $50 \%$ would reduce the ductility by about $10 \%$.

- Damping has more effects on the response at the lower excitation levels especially for the column curvature ductility. The 5\% damping is appropriate for use in the analysis. 


\section{REFERENCES}

[1] Choi, E., DesRoches, R. \& Nielson, B., Seismic fragility of typical bridge in moderate seismic zones. Engineering Structure, 26(2), pp. 187-199, 2004.

https://doi.org/10.1016/j.engstruct.2003.09.006

[2] Padgett, J.E. \& DesRoches, R., Sensitivity of seismic response and fragility to parameter uncertainty. Journal of Structural Engineering, 133(12), pp. 1710-1718, 2007. https://doi.org/10.1061/(ASCE)0733-9445(2007)133:12(1710)

[3] Dicleli, M. \& Bruneau, M., Seismic performance of single-span simply supported and continuous slab-on-girder steel highway bridges. Journal of Bridge Engineering, 121(10), pp. 1497-1506, 1995. https://doi.org/10.1061/(asce)0733-9445(1995)121:10(1497)

[4] Avşar, Ö., Fragility based seismic vulnerability assessment of ordinary highway bridges in Turkey, Ph.D. Thesis, Department of Natural and Applied Sciences, Middle East Technical University, Ankara, Turkey, 2009.

[5] Aviram, A., Mackie, K.R. \& Stojadinovic, B., Effect of abutment modeling on the seismic response of bridge structures. Journal of Earthquake Engineering and Engineering Vibration, 7(4), pp. 395-402, 2008.

https://doi.org/10.1007/s11803-008-1008-3

[6] Tavares, D.H., Seismic risk assessment of bridges in Quebec using fragility curves, Ph.D. thesis, University of Sherbrooke, Sherbrooke, Quebec: Canada, 2011.

[7] Computers and Structures Inc., SAP 2000 Integrated Software for Structural Analysis and Design, V14, Berkeley, California, 2000.

[8] McKenna, F. \& Feneves, G.L., Open system for earthquake engineering simulation, 1.6.2 Edition, Pacific Earthquake Engineering Research Center: Berkeley, California, 2005.

[9] ATC-32., Improved seismic design criteria for California bridges: Provisional recommendations. Applied Technology Council: Redwood City, California, 1996.

[10] Caltrans., Seismic design criteria, version 1.7. California Department of Transportation, Sacramento: California, U.S, 2013.

[11] Kelly, J.M., Earthquake-Resistance Design with Rubber, 2nd edn., Springer: London, 1997. https://doi.org/10.1007/978-1-4471-0971-6

[12] DesRoches, R., Leon, R.T. \& Dyke, S., Response modification of bridges. MAE Center Project ST-12, MAE report 30-08. MAE Center: Illinois, U.S, 2003.

[13] Canadian Standards Association (CSA). Canadian Highway Bridge Design Code (CHBDC), CAN/CSA S6-06. Canadian Standards Association, Rexdale, Ontario: Canada, 2006.

[14] Mander, J.B., Priestley, M.J. \& Park, R., Theoretical stress-strain model for confined concrete. Journal of Structural Engineering, 114(8), pp. 1804-1826, 1988. https://doi.org/10.1061/(ASCE)0733-9445(1988)114:8(1804)

[15] Wilson, J.C. \& Tan, B.S., Bridge abutments: formulation of simple model for earthquake response analysis. Journal of Engineering Mechanics, 116(8), pp. 1828-1837, 1990. https://doi.org/10.1061/(ASCE)0733-9399(1990)116:8(1828)

[16] Kotsoglu, A. \& Pantazopoulou, S., Modeling of embankment flexibility and soil-structure interaction in integral bridges. Proceedings of the 1st European Conference on Earthquake Engineering and Seismology, Geneva, Switzerland, 2006. 
[17] Naumoski, N., Heidebrecht, A.C. \& Rutenberg, A.V., Representative ensembles of strong motion earthquake records. EERG Report, 93-1, Department of Civil Engineering, McMaster University: Hamilton, Ontario, Canada, 1993.

[18] Naumoski, N., Heidebrecht, A.C. \& Tso, W.K., Selection of representative strong motion earthquake records having different A/V ratios. EERG report, 88-01, Department of Civil Engineering, McMaster University: Hamilton, Ontario, Canada, 1988.

[19] Halchuk, S., Adams, J. \& Anglin, F., Revised deaggregation of seismic hazard for selected Canadian cities. Proceedings of the 9th Canadian Conference on Earthquake Engineering, Ottawa, Ontario: Canada, pp. 420-432, 2007. https://doi.org/10.4095/223221

[20] Pan, J., Agrawal, A.K., Ghosn, M. \& Alampalli, S., Seismic fragility of multispan simply supported steel highway bridges in New York State. I: Bridge modeling, parametric analysis, and retrofit design. Journal of Bridge Engineering, 15(5), pp. 448-461, 2010. https://doi.org/10.1061/(ASCE)BE.1943-5592.0000085 